\title{
Social Sharing and Ongoing Narratives Provide Potential Pathways to Enhance Daily Health: Timely Perspectives from the UK and Japan (LifeStyle by Design: Virtual Living Lab)
}

\author{
Chris D Beaumont* \\ Institute for Future Initiatives, LifeStyle by Design, The University of Tokyo, Japan
}

Submission: January 25, 2021; Published: February 03, 2021

*Corresponding author: Chris D Beaumont, Institute for Future Initiatives, LifeStyle by Design, The University of Tokyo, 7-3-1 Hongo, Bunkyo-Ku, Tokyo 113-0033, Japan

\section{Abstract}

In the latter part of the twentieth century there was, in some developed markets, a reevaluation of the basic definition of healthcare. This led to a fundamental shift from a treatment orientation to a prophylactic stance and expanding self-medication. Social cost drivers were part of this transformation as well as an increasing recognition of the impact and importance of lifestyle-related disease. This led to a broader and more dynamic view of health that needed improved health literacy so that individuals could make informed lifestyle choices.

Attitude naturally drives behavior and the seminal work that established the 'Positive Health' initiative offers a coherent framework to effect healthy lifestyle behaviour. Social media, and social sharing of healthy lifestyle can act as both a catalyst for, and an accelerator to, the take-up of new such choices. Understanding what is important to people enables policy makers and educators to engage with communities in a relevant meaningful and effective manner. The narratives that are shaping our digital lives can be the basis of behavioural shifts that can enhance people's QOL.

During a period of unprecedented and rapid changes in people lives, caused by the covid-19 pandemic, this research, in Japan and the UK, tracks some of the narratives that can enhance a 'Positive Health' narrative. To 'engage with engagement' it is not simply having the appropriate content, but it is also critical to convey the appropriate tone. This is dramatically illustrated by the emotional dynamics at a time of perceived vulnerability / uncertainty during 2020 global pandemic.

Keywords: Narratives; Positive health; Self-medication; Affect; QOL; Informed choice; Social; Sharing; Empowerment

\section{Introduction}

A core tenet of The University of Tokyo's LifeStyle by Design research initiative is the increasing need to empower the individual to make an informed choice about their own healthy life options. To execute this policy demands greater health literacy amongst the population. As self-medication and healthy lifestyle choices become increasingly important social sharing of new ideas and practices can readily go viral [1]. This will have the potential to drive major attitudinal and behavioral shifts that enhance 'healthspan', rather than just longevity.

Taking a LifeStyle by Design stance will improve an individual's QOL (Quality of Life) and potentially transformative and pervasive for public and private sector stakeholders, alike. It is widely accepted that roughly 60 percent of mortality and 80 percent of the

global disease burden are a function of just four LifeStyle choiceslack of exercise; poor nutrition; smoking and alcohol abuse.

As countries try to balance their social health costs, especially in ageing demographies, the increasing need for self-medication necessitates that policy align with the attitudinal shift from a treatment to a prophylactic priority in healthcare. As such, the longstanding (from 1948; [2]) World Health Organisation's (WHO) definition of healthcare:

'Health is a state of complete physical, mental and social wellbeing and not merely the absence of disease or infirmity' 
is at odds with empowering the individual to make personal and potentially ambiguous choices regarding their own health.

\section{Social Sharing Narratives}

The covid-19 pandemic has magnified the importance of science and technology innovation to create a new and sustainable society. It has also illustrated that any communications must be inclusive and understood and embraced by multiple constituencies to have a coherent effect. The diffusion of new ideas is greatly enhanced by the almost ubiquitous participation in social. Indeed, narratives and social media are integral parts of today's connected world. Critically, trust is paramount as it is amplified in a social setting and more than ever people find trusted voices in their networks.

State-of-the-art communication science, driven by AI, can classify the utility of different narratives. They should be viewed as complex, organic structures, with unique behaviours and characteristics. Most of today's, digital conversations, [82 percent [1]] can be viewed as Transient and have no impact. Practically it is also possible to identify Timeless and Transformational narratives that can effect change, implement policy, and create sustainable value. Significantly, this allows one to identify, at any time, what is important to people, so that one can readily participate with topical conversations in a relevant and credible manner; to 'engage with engagement'. It is more effective and efficient to be part of the on-going story rather than to try to intrude from outside, which has historically been the traditional mass communication norm.

LifeStyle by Design proposes to leverage social media to ensure the effective and efficient delivery of the appropriate narratives, in context, to different constituencies. It is anticipated that this will help create Community Value. We began in mid-2019 to benchmark twenty key narratives [1] in the UK and Japan, to draw scalable communication implications for policymakers and public and private institutions, alike. The original premise was to understand what people wanted and that would enable innovation to magnify and annex on-going trends. Beyond creating a benchmark of attitudes and behavior, to monitor the mood of society, it was also intended to be comparative in nature focusing on both Japan and the UK, to help affect policy or monitor any subsequent action plan. Naturally one can hypothesise material differences in the nature of the narratives associated with LifeStyle heath choices and self-medication, not only because of cultural differences, but also due to differences in primary healthcare provision between the two countries. For example, the primacy of the General Practitioner as the interface for the patient / family in the UK.

Traditional consumer / market research is by its' very nature akin to looking in the rear-view mirror while driving. A different approach adopted for LifeStyle by Design to explicitly extract insights from on-going global narratives. To do this we chose
Significance System's proven and proprietary platform earth.ai, which analyses millions of behavioural interactions with content, to model human interaction, and to provide an objective read on engagement, media power, and the authentic, emotional drivers of (new) behaviour. It can sense and quantify over 400 named emotional states, in response to any story. The process considers all open data online as contending for consideration. Significance Systems follow a computational-reductionist approach applying multiple layers of processing to identify and extract humanmeaningful social-signaling structure within the petabytes of raw topical data available to the first stages of our process. This process dramatically reduces the volume of data to which they then apply computationally intensive processes such as detailed grammatical analysis. The textual content is interpreted within an affect model. As such the understanding of the emotional depth of the narrative, allows for better understanding and connection with people.

The core premise, explore LifeStyle by Design innovation opportunities, is that social sharing can be more authentic, and trustable than traditional forms of mass communications and can drive real world outcomes, it is now possible, with big-data based communications insight, to;

a) Objectively explore these narratives to understand the drivers and dynamics of changing behavior and consensus;

b) Probe what people value and feel are more important;

c) Establish how new solutions can be effectively introduced to create new and better behaviours.

To 'engage with engagement' it is not simply having the appropriate content, but it is also critical to convey the appropriate tone. This is dramatically illustrated by the emotional dynamics at a time of perceived vulnerability / uncertainty during 2020 global pandemic, when it is evident that, with conflicting policy options, unclear and sometimes contradictory messages only exacerbated the difficult situation. Figure 1 shows the affect associated with covid-19 from March 2020 when the country went into the first lockdown through to mid-January 2021.

Affect is a rich measure of the emotional tone of the narrative. It is felt emotion which is a powerful descriptor of future behaviour. Below the horizontal we see negative emotions dominating the positive senses (above the vertical). Initial panic (red) was replaced by fear, grief, despair and resignation, and material periods of confusion and anger. People's resilience (above the vertical) came through with a greater sense of belonging helping to maintain hope and create optimism. One clear learning in coping with the pandemic has been the need to have a positive outlook, to obviate the heightened negativity. Anxiety and anger has been exacerbated by confusing, contradictory messages from local and central government officials. The Guardian [3] links this confusion, with lockdown rules changing on average less than every 5 days on average, for the 10 months since March 2020. 


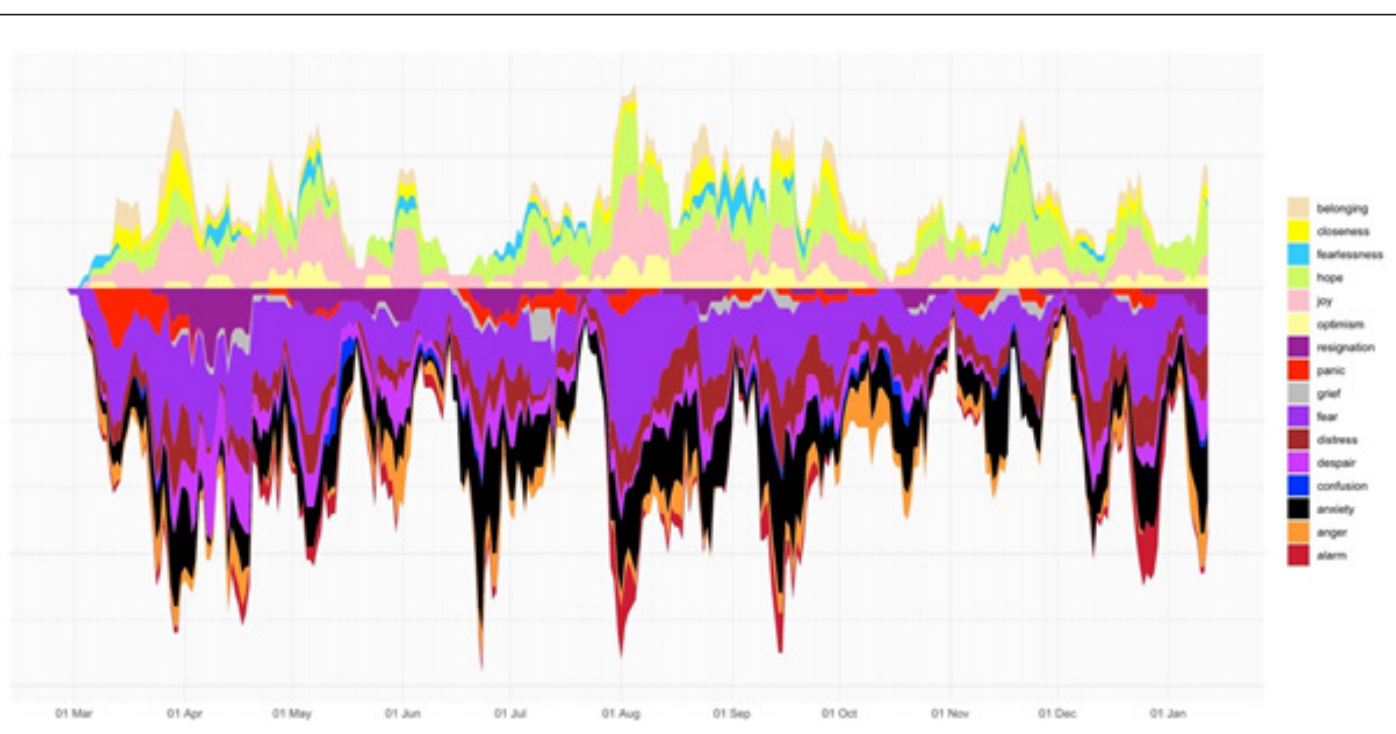

Figure 1: Covid-19 Affect in the UK (March 2020 -January 13th 2021).

\section{Positive Health}

In line with this, in name and reality, the seminal work [4] that resulted in the 'Positive Health' initiative is reflective of a prophylactic stance regarding health. Critically, it offers a potential, patient-centric, framework of health [5] in which social sharing can enhance its take-up and diffusion. This represents a major transformation from the WHO's definition of health.

The dynamic concept of health as espoused by Positive Health offers a broad perception of health (Table 1) that can readily facilitate prioritizing macro policy decisions. That said, it helps support the individuals' own direction and is wholly consistent with the broader challenges outlined in 'The 100 Year Life' [6]. In practice, it can be readily used for a subjective assessment of one's state. Critically it facilitates the patient taking the lead and setting their own actions, to reflect what is important to them. Huber [5] devised a simple 'spider chart' to visualize the results, at any given time. The basis of the spider chart are the 6 main dimensions summarized in Table 1.

Table 1: 'Positive Health': Categorization of six main dimensions and thirty-two aspects of health.

Social and societal participation: Social and communicative skills; Meaningful relationships; Social contacts; Experiencing to be accepted; Community involvement; Meaningful work.

Daily functioning: Basic Activities of Daily Living(ADL); Instrumental ADL; Ability to work; Health literacy.

Bodily functions: Medical facts; Medical observations; Physical functioning; Complaints and pain; Energy.

Mental functions and perceptions: Cognitive functioning; Emotional state; Esteem/self-respect; Experiencing to be in charge/ manageability; Self-management; Resilience, SOC (sense of coherence).

Spiritual / Existential dimension: Meaning / meaningfulness; Striving for aims/ideals; Future prospects; Acceptance.

QOL: Quality of life/well-being; Experiencing happiness; Enjoyment; Perceived health; Flourishing; Zest for life; Balance.

The sense of supporting the individuals own direction is, Hasegawa [7] notes, like the Japanese notion of ikigai. She speaks to the shift in emphasis of Positive Health from 'restoring to normal' to 'support ability to adapt'. Although there is no direct translation of ikigai in English it connotes sense of purpose in life or happiness in living and the secret has been the focus of international best seller by Garcia \& Miralles [8]. Empowering the individual to the take the lead naturally requires a change in the role of the healthcare professional, but it can be envisaged it will reduce the need for care.

\section{Narratives that can Shape our World}

The benchmark primary research began in June 2019, with a first wave of the LifeStyle by Design narratives in Japan and the UK; followed by a second wave in December 2019; with a special third wave, April 2020, when the UK was in lockdown and Japan had the national emergency in place. Subsequent waves included in this paper were in June and December 2020. This is the basis of what is referred to as the LifeStyle by Design, Virtual, Living Lab [9]. 
The vast majority of narratives, are Transient (82\%). Such narratives will fall away without significant investment. These are poor choices for communications, since as issues, they are not expected to persist or grow. Strategically, such narratives are often easy to 'own', but they must be driven, or connected to greater relevance and/or differentiation, to have any longterm value. Tribal (11\%) narratives are characterised by intense debate, being driven by personal experiences or commercial perspectives, bringing divergent POVs. The vast majority of this debate, therefore has no impact. Although it is easy to be a participant, it is far more difficult to be a player or leader in such narratives.Those narratives that have the greatest potential utility are Transformational and Timeless. Transformational (2\%) narratives are characterised by intensely, engaged experiences with strong timeless themes. These narratives are fast-changing, yet potentially result in lasting transformation of the world. Timeless (5\%) narratives are expected to persist or grow. They are characterised by long-term, deep engagement These narratives are good choices for communication activities. If one considers the narratives of the top 100 brands / companies then their effective communications strategies are focused. One sees Timeless engagement representing at least 90 percent of the narratives [10].

In tracking narratives that can shape our world, we recognize explicitly that:

a) popular stories affect individual and community behavior. b) improve decision-making comes by knowing and addressing what people feel is important.

c) relevant and timely communications, in context, can stimulate change in perception and behaviour.

d) not just content but tone is important has been exemplified by changing affect during covid-19 (Figure 1).

To leverage the strong story, it is now possible to go beyond traditional media planning considerations and focus on the strong narrative. Simply
a) Know what to say;
b) How to say it;
c) Who to say it to;
d) Where to say it.

For this paper, a subset of the 20 narratives [1] being benchmarked, in Japan and the UK, is considered. These are skewed towards the notion of 'Positive Health':
a) My Community (私のコミュニティ).
b) Personal Activity (個人的な活動).
c) Wellness (健康) \#3.
d) My Resilience (私の回復力).
e) Motivation (動機).
f) Personal Optimism(個人楽観主義).

Table 2: Dynamics of narrative classification June $2019 \rightarrow$ December 2020.

\begin{tabular}{|c|c|c|c|c|c|c|}
\hline \multirow{8}{*}{ Japan } & \multicolumn{6}{|c|}{ Landscape Category } \\
\hline & Narrative & Jun-19 & Dec-19 & Apr-20 & Jun-20 & Dec-20 \\
\hline & 私のコミュニティ & & & & & \\
\hline & 個人的な活動 & & & & & \\
\hline & 健康 & & & & & \\
\hline & 私の回復力 & & & & & \\
\hline & 動機 & & & & & \\
\hline & 個人楽観主義 & & & & & \\
\hline UK & My Community & & & & & \\
\hline & Personal Activity & & & & & \\
\hline & Wellness & & & & & \\
\hline & My Resilience & & & & & \\
\hline & Motivation & & & & & \\
\hline & Personal Optimism & & & & & \\
\hline
\end{tabular}

\begin{tabular}{|l|l|}
\hline Timeless \\
Transient \\
Transformational \\
Tribal \\
Timeless/Transient \\
\hline
\end{tabular}


To develop the narrative Landscapes, we look at all online sources, in Japan and the UK respectively, up to the date of the research wave. There is no time window. So, depending on the specific narrative, which self organises, it could be dominated by recent content ... or not. The period of study, June2019 to December 2020, saw unprecedented and dramatic changes in people's behaviour, with covid-19 becoming a social media virus as well as a biospheric virus. Already social and political commentators are referring to the tectonic shift created by the pandemic in terms of different era BC, DC and AC [Before- During- and After Covid-19] [11]. During this tumultuous period, with minds altered, opinions changed, and attitudes adjusted, it is not surprising that some of the narratives themselves took on different characteristics (Table 2).

Some differences are evident in both the classification of the narratives chosen above, between Japan and the UK, and the extent to which a particular narrative has been stable over the study period. Of all the narratives benchmarked it is evident that at present there is higher average engagement for the narratives in the UK [1]. For the UK, with the exception 'Personal Optimism', all the other narratives studied are Timeless and therefore of potentially value to effect change. In the case of Personal Optimism it begin as Transient, perhaps because of the uncertainty around Brexit in June 2019; became Tribal after the conservative government majority in the election in December 2020, but by mid-2020 was Transient it was only in early December that the first vaccine was approved in the UK. [The UK was the first country in the world to approve the Pfizer/BioNTech vaccine].

With relatively weaker levels of engagement in Japan, only “My Community', 'Personal Activity' and 'Wellness' are broadly Timeless in Japan, and the remainder ('My Resilience', 'Motivation', 'Personal Optimism') are Transient. A priori the Timeless narratives currently have the most potential to affect attitudes and behavioural shifts. That is not to say that during the study period the affect around these narratives remained constant. One practical advantage of this Virtual Living Lab is that the research waves can be as regular as necessary; our Japan and the UK comparative benchmark has 2 waves a year; while the information on the affect associated with covid-19 in the UK, is tracked daily.

In June 2019 'My Community' in Japan is Timeless but has poor definition (weak content efficiency) (Figure 2). Content Efficiency is a measure of the extent to which the existing narrative content is significant. High content efficiency means that much existing content is significant, whereas a low score means there is a gap between the needs of the narrative, and the currently-created content. Affect Orientation (Figure 3) is a measure of the degree to which the narrative stimulates an emotional response: active or passive, positive or negative. Most narratives are simply neutral, and do not provoke any emotional response. 'My Community' which is driven by an active, negative engagement, will polarise opinion. Although it has the power to grow, to maximise longterm power, it must transform from destructive and oppositional, to being viewed in positive and creative way. The analyses shows that YouTube is the media with most power around the 'My Community' narrative. Figure 4 shows how this has been transformed during the pandemic so that the 'My Community' narrative projects a sense of delight being both active and positive.

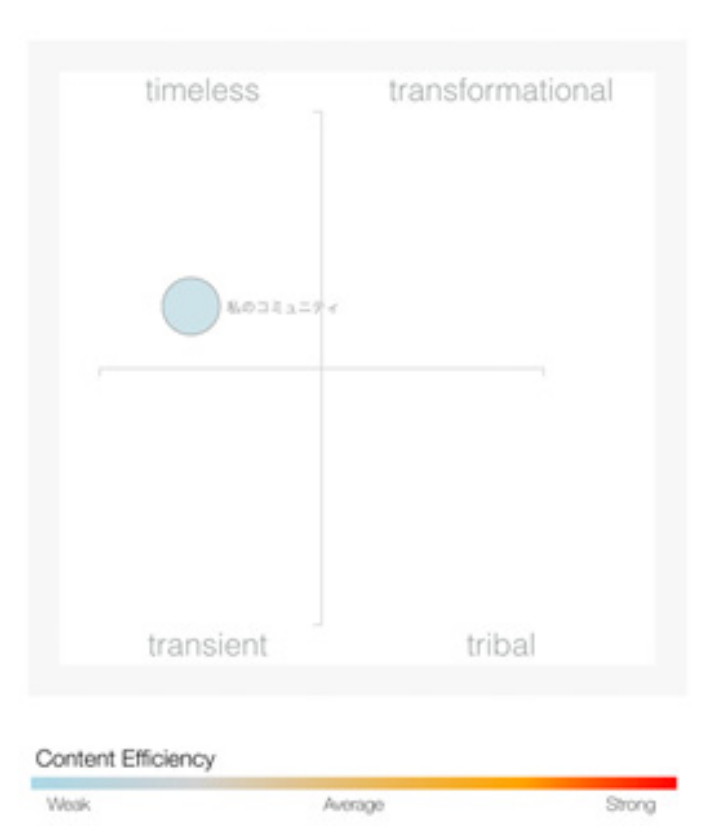

Figure 2: 'My Community' Narrative Landscape (Japan June 2019). 
Figure 3: ‘My Community’ Affect Orientation (Japan June 2019).

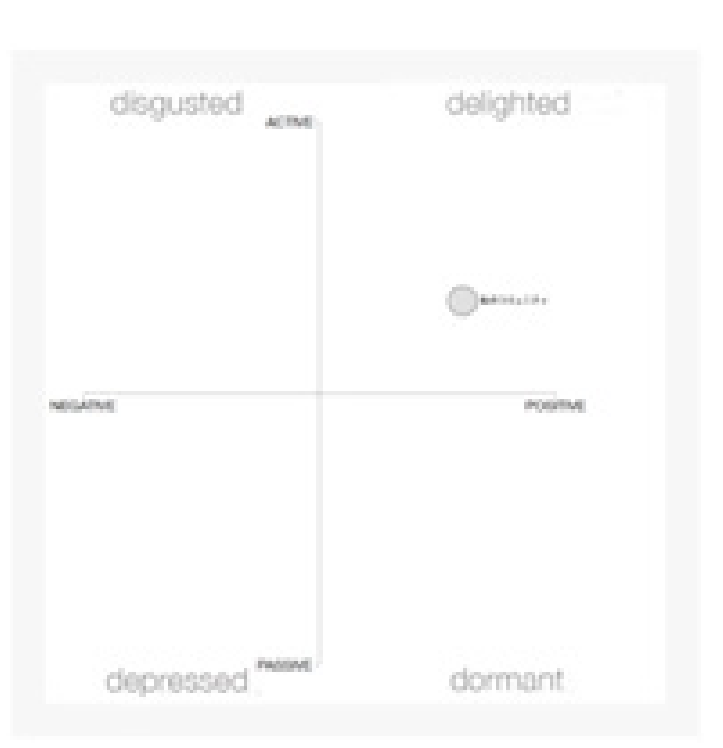

Figure 4: ‘My Community’ Affect Orientation (Japan December 2020).

Understanding of the emotional resonance of the narrative, assists in the development of strategy for both content creation and curation that can effectively disperse new ideas. Affect is a rich measure of the emotional tone of the significant content. Understanding of the emotional drivers empower you to better understand, and respond appropriately to, the emotional impact of the narrative. This is portrayed in Figure 5 for 'My Community' in Japan in June 2019.
In Figure 5, positive emotions are highlighted in green, whereas negative emotions are red. If there is a clear tonality to the emotions expressed, such as expectation or apprehension, these are shown in purple.The intensity of the colour indicates the intensity of each emotion. The width of each arc reflects the degree to which the named emotion contributes to the overall emotional response. Broad emotions, such as fear and love, are closer to the centre of the chart. The more subtle emotions, which 
contribute to those broad emotions, are shown in the concentric rings further out. Moving out from the centre, each ring shows a further level of detail. From June 2019 to December 2020 the affect around 'My Community' becomes noticeably more positive, although expectations and hope are somewhat weaker (Figure
6). The dislike coming from jealousy and envy that was evident at the start of the study (Figure 3), has disappeared as the sense of community became a more practical support, through closeness, during the unprecedented changes, such as teleworking, caused by the pandemic.

Figure 5: 'My Community' Affect (Japan June 2019).

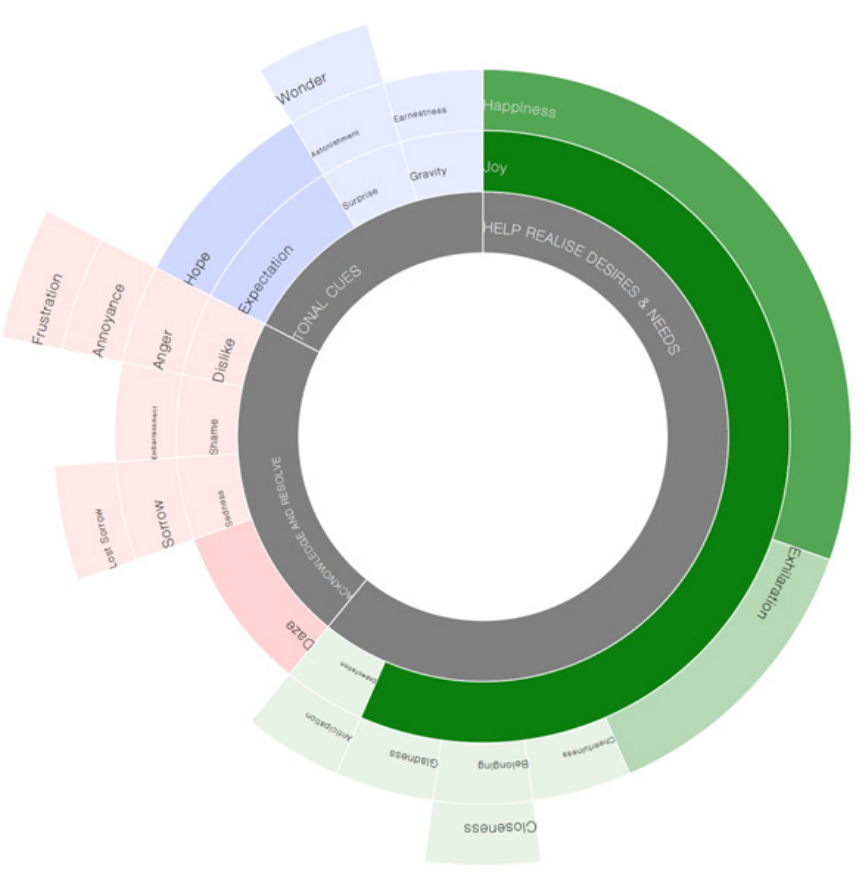

Figure 6: 'My Community' Affect (Japan December 2020). 


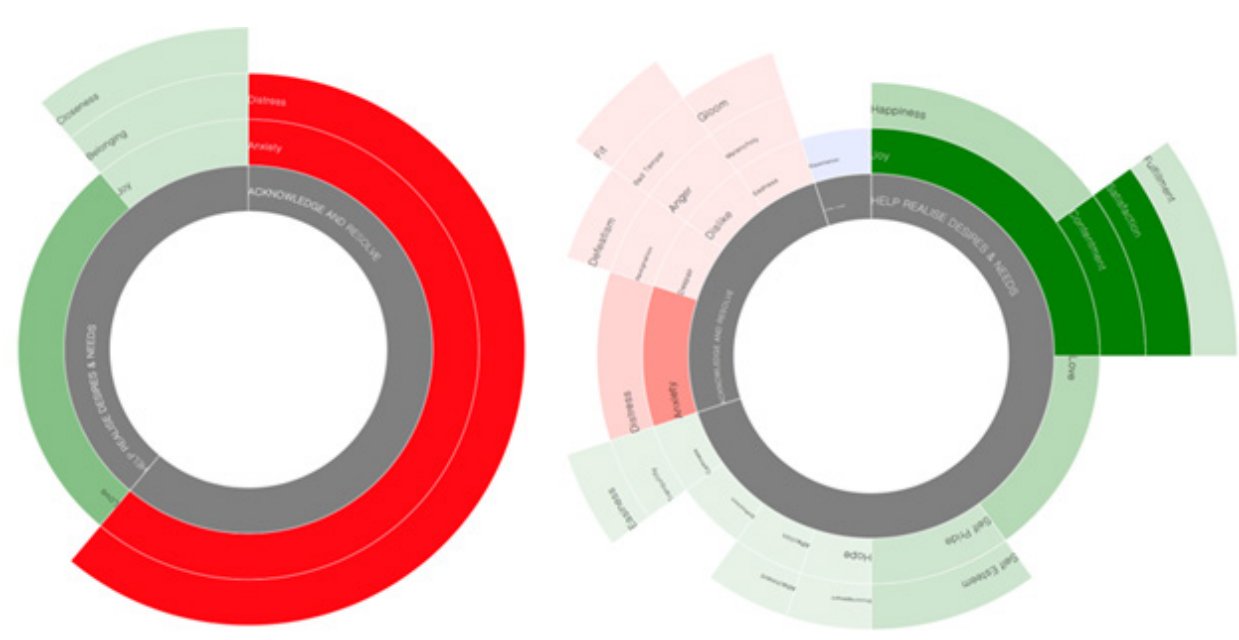

Figure 7: 'My Community’ Affect (The UK, June 2019 \& December 2020).

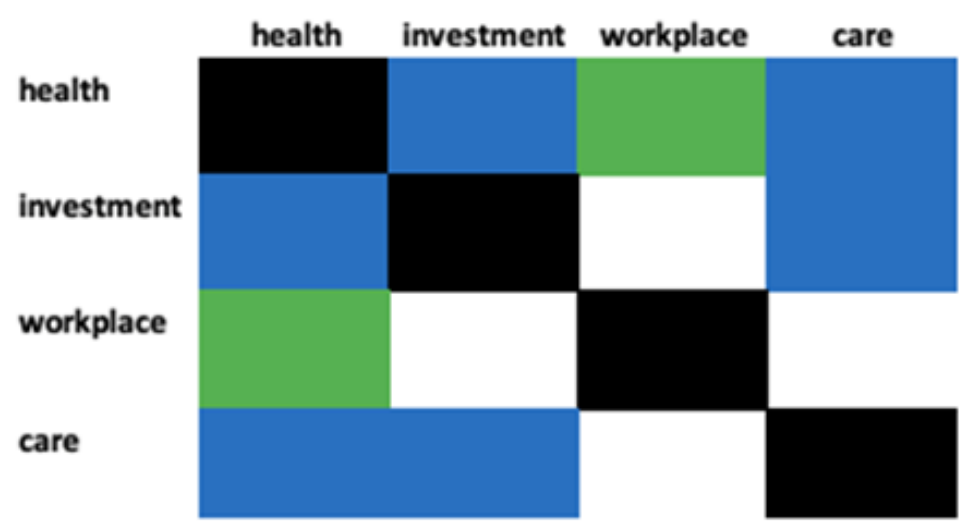

Figure 8: 'Wellness' in the UK; Key topics and relationships (December 2020).

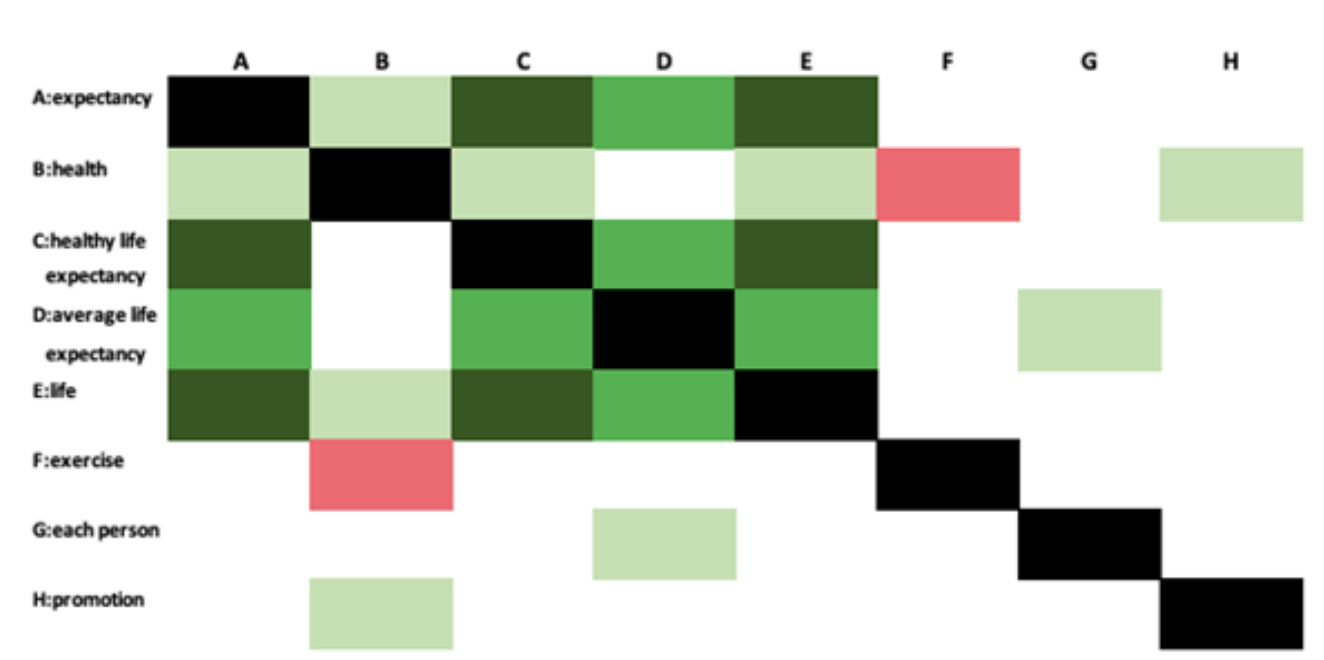

Figure 9: 'Wellness' in Japan; Key topics and relationships (December 2019). 
In broad terms a similar pattern can be seen over time in the UK with "My Community' becoming more important to the resilience of the nation during the pandemic. In June 2019, the Affect Orientation was more active and negative than in Japan (Figure 3), indicative of the disgust and opposition being stimulated by the Brexit debate. By June 2020, there is evidence of a sense of satisfaction and content, as well as pride providing hope to overcome the defeatism that drives, resignation and despair (Figure 7), as the Affective Orientation has become positive, but neither active nor positive.

With enforced isolation the pandemic has triggered reflection, soul-searching and friendship has been redefined and taken on new forms Not surprisingly, the affect around the Family, is both active and positive and despite being surprised and astonished by the situation there is a sense of calmness, love and joy in the family unit. Covid-19 is first a human tragedy, and we are witnessing universal human values of love, purpose, and connectivity uniting us. We can see that reflected in the broader narratives tracked, in the UK, by LifeStyle by Design's Virtual Living Lab, where in December 2020 'Personal Friendship', 'Personal Bonding', and “Personal Satisfaction' are all Transformational. As we look to the future, we should support the things that bind us together, and invest in our communities at scale. We can imagine that role of convenience stores, especially in Japan, will have the potential to become more integral to daily 'community' living, community health, and contactless experiences; less about casual shopping but more mainstream as people are now concerned about dining out and queueing in supermarkets. Ito-Yokado have recently announced they will start a nationwide mobile supermarket channel in 2022 to help 'stay-at-home' consumers have access to daily perishables.

Our study period has seen abrupt and fundamental changes in 'Personal Activity'. In June 2019 the affect orientation of 'Personal Activity' had active, but negative engagement, which can polarize opinion. The strongest impact on topical engagement was found at http://news4vip.livedoor.biz. By December 2020 the affect orientation of the 'Personal Activity' narrative had changed to be active and positive and therefore had created some momentum with its positive engagement. The most powerful content driving the narrative was found at Yahoo Japan. During the same period a similar trend could be seen in the UK. One sees similar shifts in emotional cues from negative to positive, but they have also become weaker, perhaps reflective of the increasing lack of 'real' control people have over their time.

At the heart of LifeStyle by Design's interest in 'Positive Health [7] is the notion of Wellness. In both countries Wellness is a Timeless narrative which suggests that it has long term and deep engagement potential and can be driven by a small number of key players, leaders, who are considered experts and authorities. The affect orientation of Wellness is positive and active, while most narratives are simply neutral and do not provoke any emotional response. Therefore, if one magnifies the enthusiasm, optimism and energy of this narrative then it can grow further and be adapted to drive meaningful behavior. However, in the UK it is relatively well defined compared to Japan. In both countries YouTube has a significance influence as the media that drives the category but in Japan it is also evident that local culture (cf. manga), and social media play an important role. A visual exploration of the content shows very little difference between Japan and the UK.

In the UK, in December 2019, Wellness is driven by four principal topics and themes which were interrelated and personal: Global Wellness Institute, body, wellness and weight. One year later in December 2020, the key topics have materially changed to ones which have a macro and public policy skew: health, investment, workplace and care. These are shown in matrix (Figure 8) It shows the topics which are driving emotional engagement, and the tone of the associations between them. Green indicates a positive association, and in this instance, there are no negative associations. White means a neutral connection, and blue, an association driven by anticipation and expectation.This matrix gives you an 'at-a-glance' view of the overall complexity, engagement, and tone of the narrative.

In Japan in December 2019, there were a wider number of different topics and themes (Figure 9), compared to the UK, driving emotional engagement. Many of these interrelationships were positive (as indicated by green), but (lack of) exercise and health have a negative association (red). However, the situation had changed materially one year on, in a similar way to the UK by becoming significantly less personal. The key topics with this narrative included management, Tokyo Stock Exchange, personal perspectives and work, Ministry, health, collaboration and perspective. The association between each of these key topics had, after almost a year of the pandemic, all become negative!

For many observers around the world [12], including Japan [13] there has been a heightening of mental health concerns during the pandemic. Fujieda city in Shizuoka took an unusual step for their senior residents (living alone or in care homes) as they would be unable to receive visits from family/friends. The municipality made robotic companions (PaPeRo from NEC Corporation) available for rent. Speech recognition enables PaPeRo to have conversations, and other functions enable the elderly to keep in touch with family/friends electronically. Significantly, it can be also used for health monitoring by tracking the senior's activity.

Of all the narratives tracked in the LifeStyle by Design's Virtual Living Lab, 'Motivation' in the UK has consistently been the strongest Timeless narrative tracked, as shown in the UK narrative landscape, for December 2020 (Figure 10). This may be a reflection of cultural differences between Japan and the UK, where individuality and short-termism are relatively important in the latter [14]. 


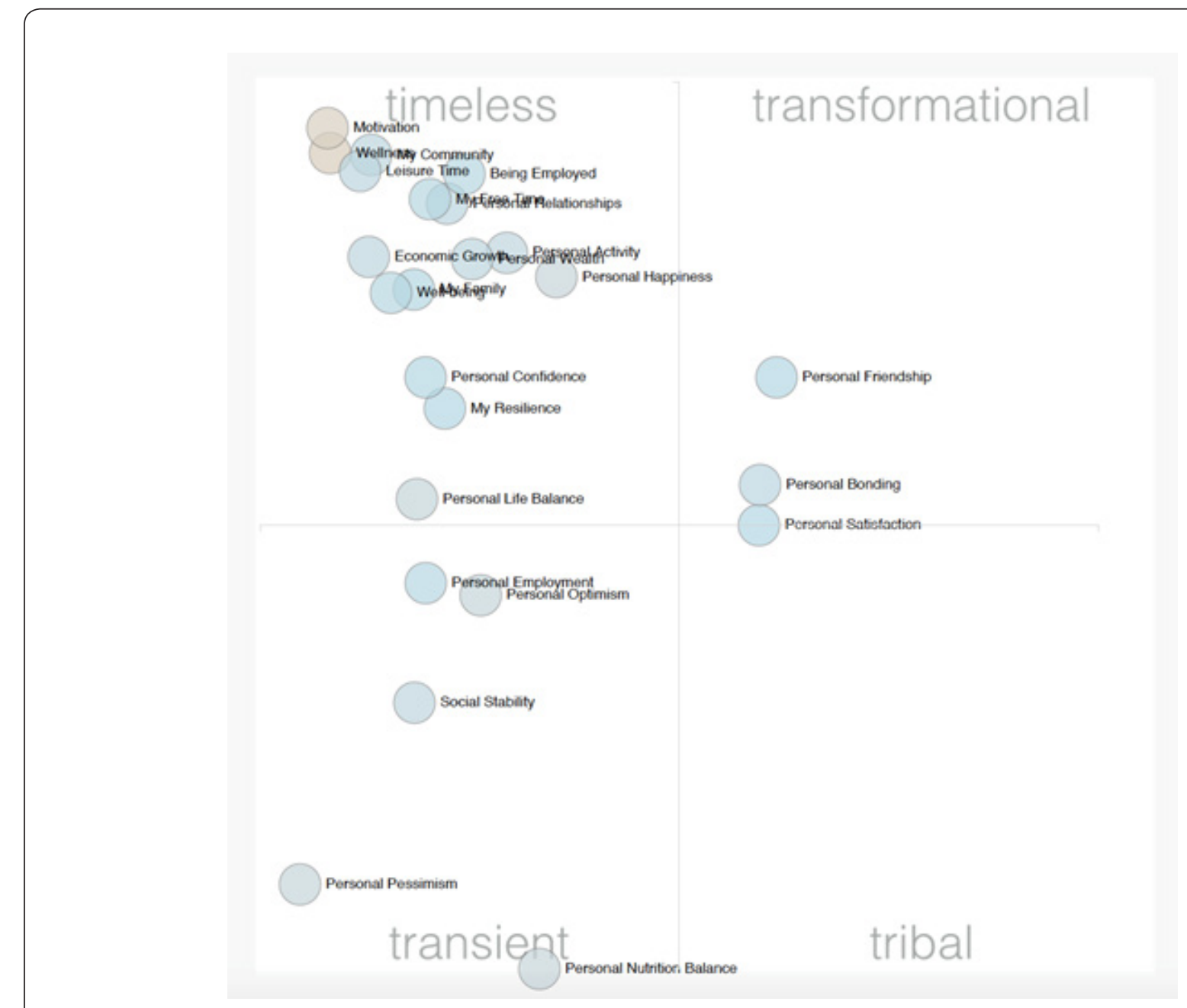

Figure 10: The UK Narrative Landscape (December 2020).

'Motivation' has consistently been driven by active, positive engagement and, as such, has momentum. Powered by enthusiasm and energy, they exhibit growth and adaptation, and drive behaviour. The positive emotions associated with 'Motivation" are about satisfaction and a sense of content, but there are some fear and dislike that has to be acknowledged and resolved. Indeed, an American worldwide employment website owned by the Japanese Recruit Co., in September 2020, produced some especially powerful content [15] that provided practical examples of different types of motivation in the workplace.

\section{Conclusion \& Implications}

Health has moved to the top of everyone's agenda as the pandemic has fundamentally, and permanently, changed how people live, work and what is important to them. In terms of technology transformation, covid-19 has in many regards fastforwarded our futures. In particular digitisation, data analytics will increase predictive analysis to be used to personalize healthcare and there will be greater consumerisation of the (contactless) patient experience, only further heightening healthy lifestyle choices.

This reframing of healthcare for society demands an improved level of health literacy amongst the population and this can be assisted by, as well as personal adoption of 'Positive Health' tracking help behavioural shifts towards, and maintenance of, health lifestyle behaviour. covid-19 has been attitudinal transformational, an equaliser, in that people are now talking more about mental health and seeking treatment when they would not have done before. There is need to create a momentum, and public and private institutions will need to accelerate digital investments and participation in ecosytems, where aligning with Lifestyle narratives is likely to become more influential and impactful.

The imperative to communicate and really connect is to ensure that the complex is simplified. Since most narratives are Transient this is also indicative that not all screen time / social 
media is productive time. Creating healthy, productive social media user experiences has become topical given the increasing reliance of social media and social sharing due to social distancing. It is driving start-up investment [16] and generating dialogue between entrepreneurs and social media specialists who believe they can create better media options, that clarify content. Some recent, social issue research [17] has identified latent desires and conflicts, through data mining, in a way that can provide greater societal understanding of subcultures, current issues and potential avenues to better governance. That said, our approach of engaging with engagement is more singular and focuses to help attitudinal and behavioral LifeStyle change. Empowering the individual through stories that go viral will have the impact outlined in Narrative Economics [18].

As people evolve from DC to AC, they are looking forward to experimenting with newer activities [18]. The pandemic has brought forward people's expectations in technology and innovation, as well as a desire to streamline their lives. Companies that recognize the new nature of convenience and community will embrace mobility, contactless experiences, and social sharing to create dynamic, future-forward behaviours.

With many different people/institutions naturally trying to provide help and advice; the imperative is to focus on what is important to people, now. Their health literacy is inadequate for the demands of self-medication, never mind in the new reality created by covid-19. Trust is an imperative but that can be gained by talking and fueling the stories that are important. The pandemic has sparked innovation, whether a start-up or an established cross-border, MNC, today's digital ecosystems enable you to focus the right message, to the right people, and in the right context. Listening is so underrated, but with a focus on objectively understanding and leveraging important stories, public policy and commercial enterprise, leaders, alike can affect change for the good. Engaging with engagement can move people, and can move markets, that will enhance people's health and QOL. The critical characteristic to enhance QOL is a positive attitude and a sense of personal empowerment [19].

\section{Acknowledgement}

The author wishes to thank Dr John Ricketts and Dr Darrell Berry, the founders of Significance Systems and according to Forbes provided the earliest example of 'social media', for their willingness to collaborate and openness to thoughtful and thought-provoking exchanges.

\section{References}

1. Beaumont CD, Ricketts J (2020) A Significant Moment in History: a virtual Living Lab., LifeStyle narratives that are shaping our world; the cases of Japan and UK 2019-20. Sustainability 12(22): 9658; Special Issue: Big Data, Knowledge Management and IoT: New Perspectives for New Challenges in Disruptive Times.

2. WHO (1948) Definition of Heath, Preamble to the Constitution of WHO as adopted by the International Health Conference, New York, 19 June - 22 July 1946; signed on 22 July 1946 by the representatives of 61 States (Official Records of WHO, no. 2, p. 100) and entered into force on 7 April 1948.

3. The Guardian (2021) English Covid rules have changed 64 times since March, says barrister.

4. Huber M (2011) How should we define health? BMJ 343: d4163.

5. Huber M, van Vliet M, Giezenberg M, Winkens B, Heerkens $Y$, et al. (2016) Towards a "Patient-Centred" Operationalisation of the New Dynamic Concept of Health: A Mixed Methods Study. BMJ Open 6(1): e01009.

6. Gratton L, Scott A (2017) The 100-year Life: Living and working in the Age of Longevity, Bloomsbury

7. Hasegawa F (2020) 病気があっても健康に!オランダ発「ポジ ティヴヘルス」「正常に戻す」から「適応する能力を支援」へ Translation: You can be healthy, even with sicknesses! Origin Holland: 'Positive Health' From 'restoring to normal' to 'support ability to adapt, JMCC -Japan Association of Healthcare Management Consultants, Contribution 2.

8. Garcia H, Miralles F (2017) Ikigai: The Japanese Secret to a Long and Happy Life, Penguin Life.

9. Beaumont CD, Ricketts J, Berry D (2021) Tracking Narratives that are Shaping Our World. Int J Environ Sci Nat Res 27(1): 556202.

10. Significance Systems: Big Data analyses.

11. Nelms B (2020) BC, DC and AC — The heroes rarely mentioned, The Citizen.

12. State of Mind special (2020) FT Special, Financial Times.

13. Asia Insight (2020) Japan's virus vigilantes underscore 'suffocating' society, Nikkei Asia.

14. Hofstede G (2001) Culture's Consequences: comparing values, behaviors, institutions, and organizations across nations $\left(2^{\text {nd }} e d n\right)$, Sage publishing, USA.

15. Indeed (2020) Career Guide, Types of Motivation in the workplace.

16. Glasner J (2021) Healthy Social Media Investment Is Happening-But It's A Two-Way Street, Crunchbase News.

17. Lee OJ, Hong H, You ES, Kim JT (2020) Discovering Social Desires and Conflicts from Subculture Narrative Multimedia. Sustainability 12(24): 10241.

18. Shiller J (2019) Narrative Economics: How Stories Go Viral and Drive Major Economic Events, Princetown University Press.

19. WPP (2021) The Future of Brands in Motion, WPP Report. 
Your next submission with Juniper Publishers will reach you the below assets

- Quality Editorial service

- Swift Peer Review

- Reprints availability

- E-prints Service

- Manuscript Podcast for convenient understanding

- Global attainment for your research

- Manuscript accessibility in different formats

( Pdf, E-pub, Full Text, Audio)

- Unceasing customer service

Track the below URL for one-step submission https://juniperpublishers.com/online-submission.php 